\title{
The distinction between worth and affordability: implications of costs and benefits for the allocation of health care resources
}

\author{
M.C. Charny and C.J. Roberts \\ Department of Epidemiology and Community Medicine, University of Wales College of Medicine, Heath Park, \\ Cardiff CF4 $4 X N, U K$.
}

\begin{abstract}
Summary: There is an important distinction between worth and affordability which remains largely unrecognized. It is widely supposed that if an economic analysis shows that the benefits of a service exceed its costs, failure to fund it is irrational and inefficient. By means of a simplified model of a health care system, it is shown that although an excess of benefits over costs is a necessary precondition for providing a service, it is by no means sufficient. If society is to make the best use of its resources in health care, worthwhile services - those which make a social 'profit' - must be compared with other such services. Since the resources available to any health care system will always be limited, it is likely that not all services whose benefits exceed their costs can be afforded, because the budget has already been committed to those worthwhile services which yield higher benefits per unit cost.
\end{abstract}

Little attention has been paid to the important distinction between the affordability and the worth of health services, perhaps because the implications are unpalatable. Two recent papers (Roberts et al., 1975; Hibbard et al., 1985) and the ensuing correspondence (Henderson, 1985; Wald \& Oppenheimer, 1985; Bagshawe, 1985; Patel \& Leck, 1985; Smith, 1985; Peto, 1985), illustrate the distinction well. Roberts et al. (1985) suggested that, in 1981/2, the National Health Service (NHS) might not have been able to afford more than $£ 14,000$ to save a life or avoid a severe disability without causing serious inequity. Hibbard et al. (1985) examined this proposition with particular reference to screening for neural tube defects (NTD). Having found that it would cost at least $£ 19,000$ to avoid the birth of a child with open NTD surviving beyond 24 hours the authors concluded that '. . . because there may be a substantial difference between what it might be worth to society to avoid the event on the one hand and what the National Health Service can afford on the other ... further development of serum alphafetoprotein screening should be discouraged in populations where the birth prevalence is below 2.5 per thousand until some notion of maximum acceptable cost to the National Health Service has been agreed'.

Correspondence: M.C. Charny M.A., M.B., B.Chir., M.F.C.M.

Accepted: 17 June 1986
In the ensuing correspondence Henderson (1985) clearly felt that screening for NTD should be provided. He offered no answer to the above question but suggested instead that it should be re-phrased to read 'can the NHS afford not to screen for open neural tube defects' and concluded that ' . . . while health authorities might not realise a financial "profit" on screening for open neural tube defects, there is reason to believe that the exchequer might and the nation would'.

This view was also advanced by critics of the article proposing that the NHS could not afford to spend more than $£ 14,000$ in $1981 / 2$ to save a life or avoid a severe disability (Wald \& Oppenheimer, 1985; Bagshawe, 1985; Patel \& Leck, 1985; Smith, 1985; Peto, 1985).

These conflicting viewpoints reflect different perspectives on the relative importance of worth and affordability in determining the allocation of health care resources. The present paper examines this distinction in more detail and suggests that while the principles on which cost benefit analysis (CBA) is based are unexceptional, such analysis has been widely misused in practice, encouraging health service planners to continue or develop services whose provision may seriously compromise the ability of health care systems to offer other services to other groups of people with a legitimate claim on that system. The outcome is most immediately recognizable in insurance based systems of health care, such as the NHS, 
in which most of the resources derive from public expenditure. CBA has an important part to play in health care planning to help maximize the output of health within existing resource constraints. However, it is now evident that with respect to the planning of some services, particularly screening programmes, CBA is actually being used to advocate inefficient resource allocation decisions. Some economists have recognised this danger - one has even felt it necessary to state that 'CBA . . . is not a form of special pleading conducted in quantitative terms' (Burchell \& Weeden, 1982).

\section{What is cost benefit analysis?}

The science of economics is based on the underlying proposition that resources are scarce. The derivation of policy from economic analysis must therefore take place within a conceptual framework which acknowledges the primacy of this assumption. CBA of, say, ten health care activities collectively costing $£ 10 \mathrm{~m}$ might well show that each is worthwhile, i.e. the benefits exceed the costs, but there may only be $£ 7 \mathrm{~m}$ available. Decisions will have to be made, not about whether some activities are worthwhile or not, but how worthwhile they are relative to one another. In other words, establishing that an activity is worthwhile is a necessary but not a sufficient condition for its provision. Such a service must also satisfy the criterion of affordability, which requires that it be shown that funding one activity produces more benefit than funding another.

Economic theory seeks to establish how resources can be used so that the maximum total benefit is achieved. Choosing the criterion of efficiency (i.e. maximizing the output obtained for a given input) is often seen as rejecting other possible criteria, such as seeking geographical or social equity. There is, however, no reason not to pursue efficiency within whatever constraints these other criteria impose (Williams, 1972). The present paper starts from the assumption that maximizing outputs for a given input is desirable, not because it seeks to reject the notion that 'social values' are as important, or more important, than efficiency, but because the arguments proposed apply whatever objectives are accepted as constraints. The reader is asked to accept no more than that once the objectives are set it would be irrational not to make the best use of the resources used.

The difficulties of measuring costs and benefits, which have been widely discussed in economic literature (Drummond, 1980; Pearce, 1971), are not considered here as they do not alter the principles proposed. Nor are the arguments advanced contingent upon their resolution.

The results of CBA are usually expressed in mon- $\frac{乛}{\mathbb{D}}$ etary units. Money is chosen only because it is a widely $\stackrel{\varrho}{C}$ accepted medium for comparing the relative value of items; it should not encourage the confusion of $\underset{\overrightarrow{3}}{\vec{F}}$ economics with accountancy. Many health benefits $\overrightarrow{0}$ cannot easily be measured, and of those which can it $\frac{}{5}$ may be difficult to express them in monetary terms which would meet with wide agreement. For the purposes of exposition, however, the present paper only examines the maximization of total benefit within constraints as a criterion for judging whether to provide a service or not, and assumes that all costs and benefits, including intangibles such as pain and suffering and the value of life itself, can be assigned monetary values which are broadly acceptable.

\section{Does the calculation of the costs and benefits of one service provide sufficient information to make decisions about its provision?}

Estimates of the costs to society of caring for someone with open spina bifida range from $£ 7,100$ to $£ 19,900$ (Henderson, 1982). Such variations are attributable, inter alia, to the difficulties of deciding what items to include as costs, how to value the items which are included, and the discount rate. These problems a not considered further in the present paper. We has chosen the evaluation of screening for NTD as ani illustration of the way in which we believe economic analysis has, paradoxically, been used to deny the existence of the very choices which economics attempts to make explicit. To illustrate the principle let us assume, for the moment, that Henderson (1982) is correct in stating that screening for NTD would produce a gross saving to society of $£ 19,900$ (at 1980 prices) per birth avoided and that his low estimate of $£ 5,200$ per case detected (Henderson, 1985) is appropriate. These figures have led Henderson, and others, to suggest that the NHS should provide this service because 'society cannot afford not to do this'. However, we believe that such a proposal only follows from the evidence advanced if it is accepted that a service is justified simply by the demonstration that the financial benefits it generates exceed its costs. It ignores the requirement of needing to maximize the benefits obtained from society's resources and it implicitly rejects the principle of opportunity cost which underpins CBA. Without this, CBA has little meaning. An opportunity cost is the cost, in terms of benefits foregone, of the best alternative use to which any particular resource can be put. We present a hypothetical example of three services which demonstrates this point. 
Opportunity costs demonstrated in a hypothetical health service which has only three interventions at its disposal

Let us suppose that a hypothetical health service has a budget limit of $£ 360,000$ and can only provide hip replacement, an expensive drug treatment for duodenal ulcer, and screening for spina bifida. $\mathrm{Hy}$ pothetical - but not unrealistic - figures for costs and benefits of these services are set out below:

1. A hip replacement which costs $£ 1200$ and can restore a 55 year old man to full productive capacity until his retirement at the age of 65 years. If it is assumed that this is the only benefit obtained, and that his salary of $£ 7000$ fairly represents the value of his production to society, then using a discount rate of $7 \%$ the benefit flowing from this investment of $£ 1200$ is approximately $£ 52,607$ or $£ 43.84$ of benefit for each $£ 1$ invested. Because the benefits greatly exceed the costs, the service is clearly worthwhile.

2. An expensive drug treatment for duodenal ulcer which costs about $£ 3000$ per ten people treated per year. In the absence of this treatment these ten patients would receive $£ 500$ worth of symptomatic treatment and one would require a seven day admission to hospital each year. If the seven day admission costs $£ 1000$, and its avoidance is the only benefit produced by the treatment, then $£ 2500$ of resources consumed has generated $£ 1000$ of benefit, or $40 \mathrm{p}$ worth of benefit for each $£ 1$ consumed. Since this service generates benefits which are worth less than its costs, it is not worthwhile.

3. Screening for spina bifida which, according to Henderson, costs $£ 5200$ and produces $£ 19,900$ benefit. This implies a benefit of $£ 3.80$ for each $£ 1$ invested. As the benefits exceed the cost, the service is worthwhile.

The consequences of choosing to fund one of these services rather than another, with the available $£ 360,000$, is shown in Table I.
If this health service were to put all its resources into hip replacement, the benefits would exceed the costs by $£ 15.42 \mathrm{~m}$. This 'profit' would then be available to fund other activities, public or private, and could be spent inside or outside the health sector. Some of this 'profit' could then be used to fund the $£ 1.38 \mathrm{~m}$ which would be required to look after the 69 children with severe spina bifida who survive because screening was not provided and the $£ 144,000$ benefits foregone which resulted from the failure to provide the expensive drug treatment. This would leave a net benefit of $£ 13.9 \mathrm{~m}(£ 15.42 \mathrm{~m}$ minus $£ 1.38 \mathrm{~m}$ minus $£ 0.14 \mathrm{~m})$ to fund other activities.

In contrast, if the budget were devoted entirely to the expensive drug treatment of duodenal ulcer, society as a whole would be worse off by $£ 17.38 \mathrm{~m}$ ( $-£ 0.216 \mathrm{~m}$ minus $£ 15.78 \mathrm{~m}$ minus $£ 1.38 \mathrm{~m}$ ).

If the budget were devoted entirely to screening for NTD, there would be a $£ 1.02 \mathrm{~m}$ net benefit available to fund other activities. However if society funds the costs of $£ 15.78 \mathrm{~m}$ which result from not providing hip replacements, and the $£ 144,000$ from not providing drug treatment for duodenal ulcer, society would face an overall net loss of $£ 14.91 \mathrm{~m}$.

If the intention is to maximize the benefits obtained with the resources available, hip replacement is clearly the service of choice. The decision to fund hip replacement in preference to screening for NTD would be taken even though the latter would generate a significant excess of benefits over costs or, to use Henderson's terminology, despite there being a profit to society. In the above, albeit hypothetical, situation, a decision to provide screening for NTD would be mistaken despite the fact that the benefits of that activity exceed its costs, because it does not consider (as economic analysis requires) a comparison with other services of benefits and costs for a given input of resources.

The above figures are not intended to prove that hip replacement should be provided or that NTD screening or treatment for duodenal ulcer should not be provided. The figures are used simply to illustrate the need to compare services with one another as well as

Table I Costs, benefits and funding of services

\begin{tabular}{lrrrrr}
\hline $\begin{array}{c}\text { Activity } \\
\text { funded }\end{array}$ & Cost $(£)$ Benefit $(£)$ & $\begin{array}{c}\text { No. of } \\
\text { outcomes }\end{array}$ & $\begin{array}{c}\text { Gross } \\
\text { benefit }(£)\end{array}$ & $\begin{array}{c}\text { Net } \\
\text { benefit }(£)\end{array}$ \\
\hline Hip replacement & 1200 & 52,607 & 300 & $15,782,000$ & $15,422,000$ \\
DU treatment & 2500 & 1,000 & 144 & 144,000 & $-216,000$ \\
Screening for NTD & 5200 & 19,900 & 69 & $1,378,000$ & $1,018,000$
\end{tabular}

\footnotetext{
Notes: 1 . Cost $=$ cost per outcome whose benefit is measured in column $2 ; 2$. Benefit = benefit per outcome, as outlined in the text; 3. Number of outcomes = the number which can be obtained with the resources available to the health service, in this case $£ 360,000 ; 4$. Gross benefit $=$ number of outcomes times benefit per outcome; 5 . Net benefit $=$ gross benefit minus $£ 360,000$ invested in the programme.

$\mathrm{DU}=$ duodenal ulcer; NTD = neural tube defects.
} 
establishing that benefits exceed costs. The decision will depend in a particular case on the services between which choices have to be made, and the way in which costs and benefits are assigned. For instance, if the duodenal ulcer treatment prevented haemorrhage and death, its benefits would be higher than those indicated, and its ranking relative to hip replacement and NTD screening might change. However, as the example indicated, the relative as well as the absolute merits of each service would still need to be assessed. Although it is artificial to constrain the decision maker to a budget of $£ 360,000$, the figure we have chosen does not alter the fact that the resources which can be allocated to any activity including health care will always be limited. Actual choices may change if more resources are allocated to a given sector but the necessity for choices always remains.

\section{The use of CBA in the management of health services}

In the above example certain simplifying assumptions are made in order to illustrate the fault in the widely accepted argument that if the benefits of a programme can be shown to exceed its costs it should always be funded. This view of the role of economics in health service management reflects a misunderstanding of the way in which CBA should be used in this context.

Ideally, the costs and benefits of every activity, whether in the health care sector or elsewhere, should be ascertained. No activity whose cost exceeds its benefit should be provided, for such activities are not worthwhile. The remaining activities are potentially eligible for funding because they are worthwhile: the benefits they yield exceed their costs. All worthwhile activities should be ranked in order of their cost: benefit ratios. Overall benefits to society will be maximized by funding first the programme with the lowest cost:benefit ratio, i.e. that which yields the greatest benefit for a given cost. Programmes are subsequently funded in order of increasing cost: benefit ratio, the return on the investment of a given amount of resource becoming steadily smaller. With unlimited resources, this process continues until the return on the investment becomes zero, which occurs when all worthwhile programmes have been funded.

\section{References}

BAGSHAWE, K.D. (1985). Lancet, i, 280 (Letter).

BURCHELL, A. \& WEEDEN, R. (1982). Practical thoughts on cost-benefit analysis and health services. Health Trends, $14,56$.

DRUMMOND, M.F. (1980). Principles of economic appraisal in health care. Oxford University Press: Oxford.

HENDERSON, J.B. (1982). Measuring the benefits of screening for open neural tube defects. Journal of Epidemiology \& Community Health, 36, 214.
In practice, however, scarcity will always mean that the process continues until all available resources have been allocated. The remaining programmes, however ${ }_{c}$ worthwhile, cannot be afforded. The calculation of costs and benefits for these programmes will show that the benefits exceed the costs, but this cannot act as ano argument that such programmes should be funded, since no resources remain unallocated.

\section{Conclusion}

CBA offers a method of responding optimally to the $\overrightarrow{\vec{\omega}}$ inescapable scarcity of resources. It establishes not $\stackrel{\omega}{\circ}$ only whether an activity is worthwhile, by showingo whether its benefits exceed its costs, but also, by doing 3 . so in a common unit, enables the worthwhileness of $\$$ activities to be ranked relative to one another. To use $-v$ the technique to demonstrate the former without ${ }_{\perp}$ regard to the latter is to make the equivalent of the epidemiological mistake of failing to compare the $\vec{\gamma}$ outcome in a study population with that of a controlo group.

This has important practical implications for the $\vec{\square}$ allocation of health care resources. Whatever criteria $\mathbb{\complement}^{\circ}$ are used to make choices between services it seems $\stackrel{\Phi}{3}$ inevitable that certain worthwhile activities cannot be

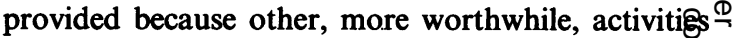
have already consumed all the available resources. $\vec{f} \overrightarrow{0}$ our view there is an emotional resistance to the unpalatable truth, intrinsic to a world of finite resou ces, that some worthwhile activities cannot be afforded. It is ironic that economics, which explicitly attempts to explore the consequences of scarcity, has been used to cloud the distinction between affor- $\frac{\circ}{\otimes}$ dability and worth.

Economic analysis and methodological problemsolving are no substitute for the creation of wealth upon which society's capacity to afford services depends. They will only help to improve the allocation of resources if accompanied by an acceptance that their purpose is as much to identify which services should not be provided as to argue the case for others. It is unrealistic to believe that a choice for one activity can ever avoid being a choice against others.

HENDERSON, J.B. (1985). British Medical Journal, 290, 712 N (Letter).

HIBBARD, B.M., ROBERTS, C.J., ELDER, G.H., EVANS, K.T. \& $\stackrel{\sim}{ }$ LAURENCE, K.M. (1985). Can we afford screening for neural tube defects? The South Wales experience. British Medical Journal, 290, 293.

PATEL, M. \& LECK, I. (1985). Lancet, i, 280 (Letter).

PEARCE, D.W. (1971). Cost-benefit analysis. Macmillan: London. 
PETO, R. (1985). Lancet, i, 281 (Letter).

ROBERTS, C.J., FARROW, S.C. \& CHARNY, M.C. (1985). How much can the NHS afford to save a life or avoid a severe disability? Lancet, i, 89.

SMITH, A.M. (1985). Lancet, i, 281 (Letter).
WALD, N. \& OPPENHEIMER, P. (1985). Lancet, i, 280 (Letter).

WILLIAMS, A. (1972). Cost benefit analysis: bastard science? and/or insidious poison in the body politick? Journal of Public Economics, 1, 199. 